\title{
Depth distribution of nitrate attenuation processes within a redox- stratified, engineered wetland biomat
}

\author{
MichAEL A. VEGA ${ }^{1,2}$, AdAM R. BRADY ${ }^{1,2,3}$, EVELYN \\ LUNDEEN $^{1,4}$, AND JONATHAN O. SHARP ${ }^{1,2}$ \\ ${ }^{1}$ Department of Civil and Environmental Engineering, \\ Colorado School of Mines, Golden, CO, USA \\ (*mavega@mymail.mines.edu) \\ ${ }^{2}$ NSF Engineering Research Center for Reinventing the \\ Nation's Urban Water Infrastructure (ReNUWIt), USA \\ ${ }^{3}$ Department of Geography and Environmental Engineering, \\ United States Military Academy, West Point, NY, USA \\ ${ }^{4}$ Maul, Foster \& Alongi, Seattle, WA
}

The unique design of shallow $(<30 \mathrm{~cm})$, open water engineered wetlands selects for a benthic biomat community that is capable of robust nitrate attenuation. Within the surficial millimeters, algal photosynthesis causes significant diel shifts in dissolved oxygen and $\mathrm{pH}$ that results in stark redox stratification with depth and time. However, it remains unknown how nitrate attenuation processes are distributed across these redox gradients and the effect that this stratification has on system performance. We hypothesized that nitrate attenuation is concentrated just beneath the oxicanoxic interface and therefore that only a thin $(\sim 2 \mathrm{~cm})$ vertical profile of the biomat is responsible for nitrate attenuation. Biomat microcosms subject to consistently oxic, oxic then anoxic, and consistently anoxic conditions were constructed to understand how nitrate attenuation rates and processes vary with depth. Nitrate attenuation occurred under all conditions though anoxic rates were $\sim 3$ times faster than oxic rates. Considerably greater nitrite production and consumption under anoxic conditions relative to oxic conditions suggests that removal mechanisms may transition from assimilatory within the oxic layer to respiratory (e.g., denitrification) beneath the oxic-anoxic interface. Experimental rates were used to inform a diffusion model that employs field constrained depth predictions of oxygen to estimate nitrate profiles. Combined field, microcosm, and modeling results collectively suggest that nitrate attenuation is concentrated within the surficial $\sim 2-3 \mathrm{~cm}$ and that nominal treatment benefits are achieved beyond overall biomat thicknesses of $\sim 2 \mathrm{~cm}$. Mechanistically investigating how nitrate attenuation processes are influenced by oxygen gradients in open water engineered wetlands, but also analogous environments (e.g., natural wetlands, intertidal sediments, mudflats, etc.), is important for understanding, predicting, and preventing the contributions of nitrogen cycling to global eutrophication and climate change. 